\title{
Fatores de virulência de Candida spp isoladas de cateteres venosos e mãos de servidores hospitalares
}

\author{
Virulence factors for Candida spp recovered from intravascular \\ catheters and hospital workers' hands
}

\author{
Nathalie Kira Tamura, Melyssa Fernanda Norman Negri², \\ Lucineide Aparecida Bonassoli ${ }^{1}$ e Terezinha Inez Estivalet Svidzinski ${ }^{3}$
}

\begin{abstract}
RESUMO
Avaliou-se o potencial de virulência de 23 leveduras isoladas de cateteres e mãos de trabalhadores em um hospital do Noroeste do Paraná. As leveduras isoladas de cateter foram mais aderentes e hidrofóbicas $(P<0,05)$ que as leveduras isoladas das mãos. Candida não-albicans expressaram com mais intensidade os fatores de virulência avaliados.
\end{abstract}

Palavras-chaves: Candida sp. Dispositivos hospitalares. Mãos. Riscos de infecção hospitalar.

\begin{abstract}
The virulence potential of 23 yeasts recovered from intravascular catheters and the hands of workers in a hospital in the northwestern region of Paraná were evaluated. Yeasts recovered from catheters presented greater adherence and were more bydrophobic $(p<0.05)$ than yeasts recovered from hands. Candida non-albicans species expressed the virulence factors evaluated more intensely.
\end{abstract}

Key-words: Candida sp. Hospital devices. Hands. Nosocomial infection risks.

A incidência de infecções hospitalares (IHs) por fungos tem aumentado substancialmente nas últimas décadas acarretando altos índices de mortalidade que atingem até $60 \%$ dos óbitos por IHs 5 .

Espécies do gênero Candida têm sido os agentes mais freqüentemente isolados, correspondem a cerca de $80 \%$ das infecções fúngicas de origem hospitalar e são a quarta causa de infecção da corrente sanguínea, conduzindo ao óbito em torno de 25 a $38 \%$ dos pacientes que desenvolvem candidemia ${ }^{12}$.

Até alguns anos atrás Candida albicans era a espécie de maior interesse clínico, contudo, paralelamente ao aumento geral das candidemias observou-se aumento das infecções de corrente sangüínea por espécies de Candida não-albicans como: C. parapsilosis, C. tropicalis, C. glabrata, C. krusei, C. guilhermondii e C. lusitaniae ${ }^{3}$.

As razões para essa inversão no padrão de distribuição das espécies ainda não foram completamente elucidadas, podendo estar fortemente relacionadas com o potencial de virulência destes microrganismos ${ }^{23}$.
A capacidade da levedura em aderir, infectar e causar doença, em conjunto é definida como potencial de virulência ou patogenicidade. Os fatores de virulência são determinados geneticamente, porém expressos pelos microrganismos quando submetidos a certas condições.

0 objetivo deste trabalho foi avaliar o potencial de virulência de leveduras isoladas de colonização de cateteres venosos e mãos de trabalhadores de um hospital com a intenção de inferir possível risco destes microrganismos em causar infecções hospitalares.

Foram estudadas 23 amostras de leveduras obtidas no período de julho de 2004 a junho de 2005, no Hospital da Universidade Estadual de Maringá, Maringá - PR, Brasil (HUM). Destas, 13 amostras isoladas de cateter venoso central (CVC), retiradas de pacientes internados na unidade intensiva de tratamento (UTI) e 10 isoladas das mãos de profissionais que atuam na UTI do HUM em coletas feitas durante a jornada de trabalho. Foi realizado pareamento controlado das amostras, com exceção de C. albicans. As leveduras foram isoladas do cateter após incubação do material por $48 \mathrm{~h} \mathrm{a} 37^{\circ} \mathrm{C}$ em caldo Sabouraud

\footnotetext{
1. Laboratório de Análises Clínicas, Hospital Universitário de Maringá. Maringá, PR. 2. Laboratório de Micologia, Universidade de São Paulo, São Paulo, SP. 3. Laboratório de Micologia Médica, Universidade Estadual de Maringá, Maringá, PR.

Endereço para correspondência: Profa. Terezinha Inez Estivalet Svidzinski. Rua Júlio Favoretto 35, Vila Esperança, $87020-600$ Maringá, PR

Tel: 5544 3261-4809, Fax: 55 44-3263-1387

e-mail: tiesvidzinski@uem.br

Recebido para publicação em 20/1/2006

Aceito em 17/1/2007
} 
seguido de subcultivo em CHROMagar Candida ${ }^{\circledR}$ (CHROMagar Company, Paris, France). Em paralelo foram realizadas coletas das mãos de profissionais através da técnica de lavagem das mãos ${ }^{13}$. As leveduras foram identificadas segundo o método clássico, baseado em análises morfológicas, fisiológicas e bioquímicas ${ }^{6}$.

Para estudar a atividade enzimática $(\mathrm{Pz})$ das leveduras foram analisadas as atividades em ágar das enzimas extracelulares conforme protocolos clássicos: fosfolipase ${ }^{8} \mathrm{e}$ proteinas $^{10}$. A formação de biofilme foi avaliada pelo método de aderência ao poliestireno segundo Shin cols $^{11}$, com leitura realizada em espectrofotometria. A hidrofobicidade da superfície celular (HSC) foi avaliada pelo método de hidrocarboneto utilizando n-hexadecano ${ }^{4}$.

Foram utilizados os testes estatísticos Mann-Whitney test e Kruskal-Wallis test (Graph Pad Prisma versão 3.0). Valores de p menores que 0,05 foram considerados significativos.

As 23 amostras de leveduras utilizadas no presente estudo incluíram C. albicans $(\mathrm{n}=7)$, C. tropicalis e C. parapsilosis $(\mathrm{n}=6)$ cada e $C$. lusitaniae e C. glabrata $(\mathrm{n}=2)$ cada. As leveduras isoladas de CVC foram mais aderentes e hidrofóbicas $(\mathrm{p}<0,05)$ que as leveduras isoladas das mãos. A atividade enzimática foi maior nos isolados de CVC, porém sem diferença significativa (Tabela 1).

Tabela 1 - Média dos testes de virulência de Candida spp isoladas de colonização de cateter venoso central e de mãos de profissionais da saúde.

\begin{tabular}{|c|c|c|c|c|c|}
\hline \multirow{3}{*}{ Espécie (n) } & \multicolumn{5}{|c|}{ Fator de virulência } \\
\hline & origem & HSC & aderência & proteinase & fosfolipase \\
\hline & & $\%$ & $\mathrm{~T} \%$ & & $\mathrm{Pz}$ \\
\hline \multirow[t]{2}{*}{ C. albicans (7) } & mão & 37,0 & 84,7 & 0,84 & 0,80 \\
\hline & CVC & 33,4 & 80,0 & 0,76 & 0,84 \\
\hline \multirow[t]{2}{*}{ C. parapsilosis (6) } & mão & 16,0 & 38,4 & 0,87 & 0,92 \\
\hline & $\mathrm{CVC}$ & 63,3 & 62,5 & 0,60 & 0,59 \\
\hline \multirow[t]{2}{*}{ C. tropicalis (6) } & mão & 40,0 & 64,0 & 0,68 & 0,80 \\
\hline & $\mathrm{CVC}$ & 64,0 & 72,3 & 0,83 & 0,82 \\
\hline \multirow[t]{2}{*}{ C. glabrata (2) } & mão & 28,0 & 7,50 & 0,60 & 0,63 \\
\hline & $\mathrm{CVC}$ & 56,0 & 88,2 & 0,80 & 0,67 \\
\hline \multirow[t]{2}{*}{ C. lusitaniae (2) } & mão & 25,0 & 27,0 & 1,00 & 1,00 \\
\hline & $\mathrm{CVC}$ & 70,0 & 49,5 & 0,76 & 0,84 \\
\hline \multicolumn{2}{|l|}{ Média (mão/CVC) } & $29,5 / 51,9$ & $51,1 / 72,5$ & $0,79 / 0,74$ & $0,84 / 0,76$ \\
\hline \multicolumn{2}{|c|}{ Valor de p (mão x cateter) } & 0,0046 & 0,0293 & 0,3321 & 0,2776 \\
\hline \multicolumn{6}{|c|}{ HSC = Hidrofobicidade da superfície celular } \\
\hline \multicolumn{6}{|c|}{ C. $=$ Candida } \\
\hline \multicolumn{6}{|c|}{$\mathrm{CVC}=$ cateter venoso central } \\
\hline \multicolumn{6}{|c|}{$\mathrm{Pz}=$ valores da atividade enzimática: forte $\mathrm{Pz}<0,64$; negativa $\mathrm{PZ}=1,0 ;$ fraca $\mathrm{Pz} \geq 0,64<1,0$} \\
\hline \multicolumn{6}{|c|}{ T\% = valores obtidos em porcentagem de aderência por meio da transmitância } \\
\hline
\end{tabular}

Candida albicans foi hidrofilica (37,0 e 33,4\%) independente do sítio de isolamento. As espécies $C$. não-albicans expressaram com mais intensidade os fatores de virulência avaliados $(\mathrm{p}=$ 0,0008 para HSC e p = 0,0263 para aderência). C. lusitaniae foi a espécie mais hidrofóbica e $C$. glabrata apresentou maior aderência, esta espécie é reconhecida pela capacidade de produzir biofilme ${ }^{11}$ e é considerada um importante patógeno hospitalar, constituindo a levedura em maior ascensão nas candidemias relatadas nos EUA e Europa ${ }^{3}$.

Candida parapsilosis isolada de CVC foi a espécie que mais expressou as enzimas proteinase e fosfolipase. As leveduras com maior atividade de fosfolipase são mais aderentes às células epiteliais e, portanto maior é a sua patogenicidade ${ }^{1}$. Há evidências que a secreção de proteinase represente um importante fator de virulência para $C$. albicans e $C$. tropicalis. Porém, para Candida parapsilosis, a correlação entre atividade proteolítica e virulência não está estabelecida, alguns estudos sugerem que a levedura produza a enzima somente sob condições experimentais e não em infecçãa\%.

É consenso que a maior parte das candidemias é precedida pelo evento de colonização do próprio paciente pela mesma espécie de levedura responsável pela infecção, contudo as infecções hematogênicas por Candida spp podem ser adquiridas por via exógena, através do contato das mãos dos profissionais de saúde, principalmente em pacientes portadores de cateteres vasculares.

Em geral as leveduras envolvidas em colonização de mãos de profissionais da área de saúde e cateteres podem ser virulentas e oferecer riscos de infecção $0^{213}{ }^{14}$. Neste estudo, as leveduras isoladas das mãos apresentaram menor potencial de virulência do que as isoladas dos CVC.

Candida albicans é a espécie mais conhecida do gênero e considerada de maior interesse clínico por ainda corresponder ao principal agente de infecções fúngicas em humanos. Porém, as espécies $C$. não-albicans são emergentes em várias partes do mundo e 0 aumento desses agentes em infecções pode estar associado a maior expressão dos fatores de virulência ${ }^{12}$.

Candida não-albicans apresentaram aderência e propriedades hidrofóbicas significativamente superiores a C. albicans. As interações hidrofóbicas estão envolvidas no processo de aderência de Candida às superfícies das células do hospedeiro ${ }^{4}$. Luo cols ${ }^{7}$ observaram íntima relação entre a aderência de espécies de Candida em superfícies e a hidrofobicidade da superfície dessas leveduras.

No Brasil e no mundo, existem vários grupos de pesquisadores preocupados com a importância das IHs por leveduras tendo em vista os altos níveis de morbidade e mortalidade. Têm sido realizados muitos estudos epidemiológicos e de resistência aos antifúngicos, porém são escassos os relacionados ao potencial de virulência desses microrganismos e talvez essa seja uma das principais causas do aumento das infecções hospitalares por leveduras.

\section{REFERÊNCIAS}

1. Barrett-Bee K, Hayes Y, Wilson RG, Ryley JF. A comparison of phospholipase activity, cellular adherence and pathogenicity of yeasts. Journal of General Microbiology 131: 1217-1221, 1985.

2. Cheng MF, Yang YL, Yao TJ, Lin CY, Liu JS, Tang RB, Yu KW, Fan YH, Hsieh KS, Ho M, Lo HJ. Risk factors for fatal candidemia caused by Candida albicans and non-albicans Candida species. BMC Infectious Diseases 5:1-5, 2005.

3. Colombo AL, Nakagawa Z, Valdetaro F, Branchini MLM, Kussano EJU, Nucci M. Susceptibility profile of 200 bloodstream isolates of Candida spp collected from Brazilian tertiary care hospitals. Medical Mycology 41: 235-239, 2003. 
4. Doyle RJ, Rosenberg M. Microbial cell surface hydrophobicity. American Society for Microbiology, Washington, 1990.

5. Hota B. Contamination, disinfection, and cross-colonization: are the hospital surface reservoirs for nosocomial infection? Clinical Infectious Diseases 39: 1182-1189, 2004.

6. Kurtzman CP, Fell JW. The yeasts: a taxonomic study. New York, 1998.

7. Luo G, Samaranayake LP. Candida glabrata, an emerging fungal pathogen, exhibits superior relative cell surface hydrophobicity and adhesion to denture acrylic surfaces compared with Candida albicans. Acta Pathologica, Microbiologica et Immunologica Scandinavica 110: 601-610, 2002.

8. Price MF, Wilkinson ID, Gentry LO. Plate methods for detection of phospholipase activity in Candida albicans. Sabouraudia 20: 15-20, 1982.

9. Ruchel R, Boning B, Borg M. Characterization of a secretory proteinase of Candida parapsilosis and evidence for the absence of enzyme during infection in vitro. Infection and Immunity 53: 411-419, 1986.
10. Ruchel R, Tgegeler R, Trost M. A comparison of secretory proteinase from different strains of Candida albicans. Sabouraudia 20: 233-244, 1982.

11. Shin JH, Kee SJ, Shin MG, Kim SH, Shin DH, Lee AK, Suh SP, Ryang DW. Biofilm production by isolates of Candida species recovered from non neutropenic patients: comparison of bloodstream isolates with isolates from other sources. Journal of Clinical Microbiology 40: 1244-1248, 2002.

12. St-Germain G, Laverdiere M, Pelletier R, Bourgault AM, Libman M, Lemieux C, Noel G. Prevalence and antifungal susceptibility of 442 Candida isolates from blood and other normally sterile sites: results of a 2-year (1996 to 1998) Multicenter Surveillance Study in Quebec, Canada. Journal of Clinical Microbiology 39: 949-953, 2001.

13. Strausbaugh LJ, Sewell DL, Tjoelker RC, Heitzman T, Webster T, Ward TT, Pfaller MA. Comparison of three methods for recovery of yeasts from hands of health-care workers. Journal of Clinical Microbiology 34: 471-473, 1996.

14. Tamura NK, Gasparetto A, Svidzinski TIE. Evaluation of adherence of Candida species to urinary catheters. Mycopathologia 156: 269-272, 2003. 